\section{PS-257 DANGER IN CHILD NUTRITION: JUNK FOODS}

${ }^{1} \mathrm{M}$ Uzun, ${ }^{2} \mathrm{~N}$ Atar, ${ }^{3} \mathrm{M}$ Kar, ${ }^{4} \mathrm{~A}$ Gündogdu. ${ }^{1}$ Child Health and Illnesses Nursing, Bulent Ecevit University, Zonguldak, Turkey; ${ }^{2}$ Essentilas of Nursing, Bulent Ecevit University, Zonguldak, Turkey; ${ }^{3}$ Nursing, Bulent Ecevit University, Zonguldak, Turkey; ${ }^{4}$ NICU, Eregli Educational and Research Hospital, Zonguldak, Turkey

\subsection{6/archdischild-2014-307384.558}

Background and aims The junk food like chocolate, sweets, savoury snacks, crisps, have high sugar and fats, but low in nutritional value. It is important to teach your children to eat more balanced, whole foods and avoid junk food. The aim of the study is to determine mother attitudes about junk food consumption of their children.

Methods A descriptive quantitative approach was used in study. The data were obtained from 200 mothers who has child in different ages by a questionnaire designed by researchers. Data was evaluated using the descriptive statistics available in the Statistical Package for Social Sciences Software (SPSS 16.0).

Results Most of the mothers were (37,5\%) between 21-25, high-school graduate $(33,5 \%)$ and housewife $(63,5 \%)$. Most of them $(93,5 \%)$ allowed their children to eat junk foods (crisps, chocolate, wafer), to buy one junk food for every market shopping (61,7\%). Mothers' prefer and knowledge affected choosing junk foods (53\%). Mothers' stocking constantly biscuit, wafer, fruit milk percent was $62 \%$. Wafer and chocolate were $62 \%$, biscuit was $32 \%$ of these stocked foods. Most of mothers didn't prepare yoghourt at home $(64,5 \%)$, and give their children artificial milk, milk products, fruit yoghourt (86\%). Mothers also stated that they eat junk foods with their children, too $(61,7 \%)$. Conclusion Mothers' knowledge, attitude and prefer about junk foods have great role in junk consumption of children. It is suggested that increasing mothers' attention about healthy child nutrition may prevent consumption of junk food.

\section{PS-258 CAN THE EXPRESSION OF CHRONIC DISEASE GIVEN BY CHILDREN BE UNDERSTOOD WITH AESTHETIC KNOWING?}

M Bayat, D Keklik, N Uslu, E Erdem, Y Sezer Efe, Z Korkmaz, O Tosun. Nursing, Erciyes University Faculty of Health Sciences, Kayseri, Turkey

\subsection{6/archdischild-2014-307384.559}

Background and aims Aesthetic Knowing provides understanding human reactions towards disease, health, events. Study was conducted qualitatively to understand what chronic disease expressed to children with chronic diseases by intern nurses with Aesthetic Knowing.

Methods Study was conducted with 25 intern nurses caring 25 children aged 9-18 years hospitalised at paediatric clinics of a university hospital in Turkey. Ethical approval and consent from students, children, parents were obtained. Aesthetic Knowing education was given to students prior to study. Students wanted children to express what it meant to have chronic disease by painting (8) or article-poem-letter (17) based on their preferences. Focus group interview was done to learn experiences of students, recorded and themes (meaning of chronic disease for children, benefits of Aesthetic Knowing, experiences of students about using Aesthetic Knowing in nursing, contribution of Aesthetic Knowing to nursing) were determined after content analysis.

Results Opinions of students about chronic disease were; fear, anxiety, concern, stress, anger, pain, feeling of guilt, impact on routines, school lives, life styles, quality of life, social and psychological support needs, future uncertainty, limitations of disease (medications, diet).

Opinions of students about benefits of Aesthetic Knowing and its usage in nursing were; entering inner world of children, understanding feelings of pain, anger, guilt, increasing empathy, trust relations, communication, provision of holistic care, improving quality of care, integrating family into care, noticing patient needs, providing patient self-expression.

Conclusions Aesthetic Knowing is recommended to use in nursing education and patient care to understand children reactions and direct care.

\section{PS-259 WITHDRAWN}

\section{PS-260 DETERMINING THE ATTITUDES OF NURSING STUDENTS TOWARDS EVIDENCE BASED NURSING}

${ }^{1} \mathrm{~F}$ Tas Arslan, ${ }^{2} \mathrm{R}$ Celen. ${ }^{1}$ Associate Professor Pediatric Nursing, Selcuk University, Konya, Turkey; ${ }^{2}$ Assistant Pediatric Nursing, Selcuk University, Konya, Turkey

\subsection{6/archdischild-2014-307384.560}

Background In order that evidence-based nursing practices can be integrated into the clinic and that the nurses have a critical perspective, the principles and the value of evidence-based practices should be given at undergraduate nursing education.

Aim This research has been conducted in order to determine the attitudes of nursing students towards evidence-based nursing. Methods The descriptive research has been conducted in Selcuk University Faculty of Health Sciences between March 1 and April 1, 2014. Research data were gathered from 2nd, 3rd and 4th grade 263 nursing students with a questionnaire form prepared by the researchers and 'The Attitude towards EvidenceBased Nursing' (AEBN) and was evaluated by average, percentage and t-test.

Results $60 \%$ of the students participating in the research were between $21-23$ years old. $57,8 \%$ of the students were taking the research course, $57,4 \%$ of weren't reading any journals of nursing, 53,6\% didn't participate in any scientific activity. The point average of AEBN was $57,33 \pm 8,88$. A statistically significant difference was found between the attitudes towards taking the research course, reading journals of nursing, participating in scientific activities, the desire to make research after graduation and the AEBN scale score. (Respectively $t=2,276, p=0,024$, $t$ $=2,174 \mathrm{p}=0,031, \mathrm{t}=2,580 \mathrm{p}=0,010, \mathrm{t}=6,856 \mathrm{p}=$ 0,000).

Conclusion It has been found that the AEBN scale score of the students participating in professional scientific studies was high. It was concluded that the practices for evidence-based nursing should be increased and inclusive education should be given so that the results can be adapted into clinical setting.

\section{PS-261 PARENTAL NEEDS IN NEONATAL INTENSIVE CARE UNIT}

A Vaskelyte, V Grigaliuniene, V Bulikaite. Nursing and Care, Lithuanian University of Health Sciences, Kaunas, Lithuania

10.1136/archdischild-2014-307384.561 
Parent participation in the nursing process significantly contributes to the overall wellbeing of a newborn and the whole family. It is important to ensure that nurses, who take care of newborns and collaborate with their family members, are well-acquainted with the influence that an infant's illness and critical condition as well as the stress have on the functioning of a family unit

The Aim To compare parents' and nurses' perceptions of parents needs in Neonatal Intensive Care Unit.

The study was conducted in Kaunas University Hospital NICU. The sample consisted of 181 parents and 37 nurses. The NICU Family Needs Inventory was used for data collection. The instrument included five following subscales of needs: proximity, information, assurance, support and comfort. Reliability of the scale was identified as 0.94 using Cronbach's $\alpha$.

The parents' needs perceived by both groups were compared within the subscales. Using Mann'o-Whitney rank test the significant differences between the parents' and nurses' assessments of individual statements were identified. The majority of statistically significant differences between parents and nurses have been found in case of assessment of proximity (75.0\%) and informational $(72.7 \%)$ needs related to the possibility for parents to be close to their newborn and to receive timely and adequate information about their newborn's health condition. Parents, if compared to nurses, assessed these needs as more important. The assessment of support needs showed the lowest number of differences $(38.9 \%)$. There was a statistically significant difference in case of the decision making needs related to the newborn care that parents identified as being more important. Nurses perceived as being more important the needs related to parent-toparent support and possibility to share feelings.

The comparison of parents and nurses perceptions of parents needs in NICU showed that there are statistically significant differences of individual statements assessment within the all five subscales.

\section{PS-262 RISK PROFILE TO PREVENT RE-ADMITTANCE TO THE NEONATAL INTENSIVE CARE UNIT}

LE Smit, MJ Hemmink, JM Wielenga. IC Neonatology, Emma Children's Hospital/Academic Medical Center, Amsterdam, Netherlands

\subsection{6/archdischild-2014-307384.562}

Background and aims Infants at the Neonatology Intensive Care Unit (NICU) of the Emma Children's Hospital/Academic Medical Centre Amsterdam are transferred to regional hospitals once they no longer need intensive care. Unfortunately, a number of these infants are re-admitted to the NICU. This study investigates the similarities between these hospitalised infants, in order to develop a way to limit the number of infants re-admitted to the NICU.

Methods The first step in the process is to classify different diagnoses for re-admittance of infants to the NICU. By using these diagnoses, and adding parameters resulting from a search of literature, a set of risk parameters can be created. This set will be used to retrospectively analyse the nursing files of infants re-admitted to the NICU within $72 \mathrm{~h}$ after discharge. The exclusion criteria used were re-admittance for phototherapy, inserting an IV or planned surgical or treatment interventions.

Results From July 2009 to July 2013, 44 infants were re-hospitalised at the NICU. Nineteen infants met the inclusion criteria. Of these 19 infants a (graphical) risk profile could be created showing the physiological (in)stability in the three days before discharge.
Conclusions This study shows that infants have different early warning signs of physiological instability. However this instability can be expressed in a risk score, which might predict the chance that the infants are re-admitted to the NICU. The NICU may thus decide to not discharge the infant for a few more days. Further research on the utilisation of the risk score is needed.

\section{PS-263 DETERMINING THE LEVEL OF AWARENESS ON CANCER IN UNIVERSITY STUDENTS}

${ }^{1} \mathrm{M}$ Kurtuncu, ${ }^{2} \mathrm{~L}$ Utas Akahn, ${ }^{2} \mathrm{~S}$ Celik, ${ }^{1} \mathrm{I}$ Alkan. ${ }^{1}$ Pediatric Nursing, Bulent Ecevit University, Zonguldak, Turkey; ${ }^{2}$ Psychiatric Nursing, Bulent Ecevit University, Zonguldak, Turkey

\subsection{6/archdischild-2014-307384.563}

Background and aim The most important reason for the high mortality rates of cancer is the low level of awareness, which leads to a late diagnosis and the treatments starting too late. For this reason, it is important for individuals, especially at younger ages, to gain awareness and integrate taking the necessary precautions into their lifestyle in order to prevent cancer and ensure early diagnosis. This study was performed with the goal of determine the levels of awareness of students studying in two different campuses of a university in the Western Black Sea Region on cancer and its symptoms.

Methods This descriptive/cross sectional study was performed in a university in the Western Black Sea Region between 01. February.2013-01. April.2013. Students studying in the 2012-2013 academic year in a university in the Western Black Sea Region formed the universe of the study. The study was performed in two separate campuses belonging to the university.

Results The average age of the students was $22.01 \pm 3.63$. While female students were the majority in the health sciences campus $(74.8 \%)$, male students were the majority in the central campus (76.5\%). 57.5\% were male. $9.6 \%$ of the students from the health sciences campus and $12.4 \%$ of the students from the central campus thought that cancer was communicable, while most of the students from both campuses knew that smoking caused cancer. It can also be seen that the rate of answering questions regarding cancer correctly was higher among students studying in the health sciences campus.

Conclusion It was determined that students who do not study at the health campus have insufficient information on cancer, cancer symptoms, and the presence of breast cancer in males and approximately half of them regarded obesity as a risk factor for cancer.

\section{PS-264 COMPARISON OF TWO MANUAL VENTILATION DEVICES ON THE PAEDIATRIC INTENSIVE CARE: THE SELF-INFLATING BAG VERSUS THE FLOW-INFLATING BAG}

M de Neef, GJ Muller, AS Kraenzlin, RM Wosten-van Asperen. PICU, Emma Children's Hospital/Academic Medical Center, Amsterdam, Netherlands

\subsection{6/archdischild-2014-307384.564}

Objective Different types of devices for manual (bag) ventilation are available. But which device is the best to use is still a matter of controversy. Most frequently used devices in Dutch PICU's include the Self Inflating Bag (SIB) and the Flow Inflating Bag (FIB). The choice of the system seems to be subjective, and depend mostly on unit policy or personal preferences. Studies 